\title{
Self-reported quality of life in patients with retinitis pigmentosa and maculopathy of Bothnia type
}

\author{
This article was published in the following Dove Press journal: \\ Clinical Ophthalmology \\ II March 2010 \\ Number of times this article has been viewed
}

\section{Marie SI Burstedt Eva Mönestam}

Department of Clinical Sciences/ Ophthalmology, University of Umeå, Sweden
Correspondence: Marie Burstedt Department of Clinical Sciences/ Ophthalmology, University of Umeå S-90I 85 Umeå, Sweden

Tel +46-90-7853774

Fax +46-90- 145997

Email marie.burstedt@ophthal.umu.se
Purpose: To assess vision-related quality-of-life subscales with objective measurements of visual function in patients affected with retinitis pigmentosa of Bothnia type (BD).

Methods: Forty-nine patients answered the NEI-VFQ-25 questionnaire. High- and low-contrast distance acuity (VA), near VA, and visual fields (VF) were measured. Weighted VA (WVA) and low-contrast (10\%) VA (WLCVA), binocular VF areas, and central scotoma were calculated. Adjusted mean subscale scores were calculated and associations analyzed.

Results: Subscale scores for general, far, and near vision, social functioning, and color vision were lowest while general health, ocular pain, and mental health were highest in the BD phenotype. The correlations were substantial and similar for WVA, WLCVA, and near vision. The degree of measured VF impairment had few associations with the different adjusted subscale scores.

Conclusion: The NEI VFQ-25 subscales were well associated with clinical vision measures depending on VA. The progression of VF defects typical for the BD phenotype does not seem to affect the self-perceived quality of life, which might indicate adaptability to this type of progressive VF loss. The BD phenotype has a significant impact on multiple domains of daily life, but there are no signs of accelerating depression related to the increasing visual impairment.

Keywords: visual function, low vision, maculopathy, RP, Bothnia dystrophy, visual cycle, RLBP1

\section{Introduction}

The loss of visual function in retinal disorders is typically assessed by clinical tests such as visual acuity (VA), visual fields (VF), and electrophysiological methods. To increase the understanding of the patients' situation and need it is also important to estimate the patients' self-perceived visual function in different stages of the disease, in addition to standard ophthalmological measurements. Self-reported visual function and health related quality of life (VRQL) are also important to evaluate and compare the retinal degenerative diseases of different phenotypes.

Bothnia dystrophy (BD) is a clinically and genetically defined variant of autosomal recessive retinitis pigmentosa (RP) associated with a missense mutation affecting the RLBP1 gene. ${ }^{1}$ There is a high prevalence of patients in northern Sweden, but RP phenotypes of the same gene have been described worldwide. ${ }^{2-5}$ The BD phenotype is characterized by early, severe night blindness, prolonged dark adaptation, and reduced macular function with decreasing VA in early adulthood. Fundus changes similar to retinitis punctata albescens, maculopathy, and peripheral retinal degeneration are found. ${ }^{6-8}$ Central and/or paracentral VF defects with relative to absolute scotomas, can be observed in the teens progressing to the peripheral borders with age. ${ }^{6}$ In $\mathrm{BD}$ the 
VF progression shows a complete or partial midperipheral ring scotoma resembling the pattern of VF progression described in autosomal recessive inherited RPs (pattern III), ${ }^{9}$ compared to the concentric loss of the VF in other phenotypes of RP.

The visual impairment of the BD patients affects their ability to perform various vision-specific functions of everyday life. In a previous study associations between several objective measurements of visual function and self-assessed visual ability were investigated. ${ }^{10}$ It was found that age and weighted distance logMAR visual acuity (WVA) were significantly associated with the 25-item National Eye Institute Visual Function Questionnaire (NEI-VFQ-25) composite score and that WVA alone was the strongest predictor of selfreported assessment of total visual function in $\mathrm{BD}$ patients.

The purpose of this study was to associate the various objective measurements of visual function with the patients' self-assessment of vision measured by the VRQLquestionnaire subscales. The aim was also to provide insight into the perceived visual function of this defined type of RP patients, and to describe the impact of vision loss caused by $\mathrm{BD}$ on everyday life, which previously has not been described. The patients in this study represent all ages and stages of the BD phenotype.

\section{Patients and methods}

\section{Patients}

Forty-nine patients, 21 men and 28 women, phenotypically and genetically affected with BD, were included in the study. All patients originated from the Västerbotten County, Sweden, and were evenly distributed in age and gender. ${ }^{10}$ The mean age of the patients was 49 years ( $\mathrm{SD}=20.8$; range 5 to 80 ). A large proportion of the patients (39\%) was legally blind (20/400 or worse), according to the WHO criteria. ${ }^{11}$ All patients were examined at the Eye Clinic, Umeå University Hospital, except for 5 participants $(5 / 49)$ who had the examination at their home clinic because of too large geographical distance to travel. The ocular examination of the patients found no significant ocular disease other than BD.

Informed consents were obtained from all subjects. The study followed the tenets of the Declaration of Helsinki, and was approved by the Ethics Committee of Umeå University.

\section{Tests of visual function}

Monocular VA was tested by Early Treatment Diabetic Retinopathy Study (ETDRS) charts at a distance of $4 \mathrm{~m}$. Participants who failed to read the largest letters at $4 \mathrm{~m}$ were tested at $1 \mathrm{~m}$. Lighting conditions were standardized, using an "ETDRS" chart illuminator cabinet no 2425
(Precision Vision $^{\circledR}$, La Salle IL, USA). VA was scored as the total number of letters read correctly and transformed to the logarithm of the minimum angle of resolution (logMAR) units. Patients with failure to read any letters were tested using counting fingers (CF), hand movements (HM), and light perception (P). For VA less than CF $0.5 \mathrm{~m}$ the following arbitrary $\log \mathrm{MAR}$ values were used $\mathrm{CF}$ in front of the eye $=\log$ MAR 2.2; HM $=\log$ MAR 2.3; $\mathrm{P}=\log$ MAR 2.5 and no light perception $=\log$ MAR $3 .{ }^{12}$

As binocular VA was not measured in this study, WVA was chosen to summarize the acuity data from both eyes of the patient into one value. ${ }^{13}$ The following method of calculation was used: VA of the better eye was weighted 0.75 , VA of the worse eye 0.25 , and the average of the two values was calculated, making up the WVA.

The five patients, who were examined at their home clinic, had their distance acuities tested with a Monoyer letter chart. Their decimal VAs were converted into a log scale using the method outlined by Holladay. ${ }^{14}$

Monocular low contrast VA (LCVA) was tested using Sloan letter logarithmic translucent contrast charts $(10 \%)$ $\left(\right.$ Precision Vision ${ }^{\circledR}$ ) at a distance of $4 \mathrm{~m}$. Participants who failed to read the largest letters at $4 \mathrm{~m}$ were tested at $1 \mathrm{~m}$. Lighting conditions were standardized as described above.

LCVA was scored as VA, ie, the total number of letters read correctly, and transformed to logarithm of the minimum angle of resolution (logMAR) units. Only 19 participants $(19 / 49 ; 39 \%)$, predominantly in the younger ages (11 to 60 years) were able to produce measurable results, when testing the LCVA chart. $\operatorname{LogMAR}=3$ was used for patients unable to read any letter on the 10\% LCVA chart at a distance of $1 \mathrm{~m}$ ). When summarizing the LCVA measurements from both eyes, weighted LCVA (WLCVA) was calculated using the same method as calculating WVA.

Binocular near vision was measured using the EDTRS near vision chart at a distance of $40 \mathrm{~cm}$ with best correction. The test distance was changed to $20 \mathrm{~cm}$, if necessary.

Visual field examinations were performed monoculary with a Goldmann perimeter using the (V-4-e), and (II-4-e) targets. The binocular VF maps were produced by merging the monocular fields of each subject with BD, using the method described by Arditi. ${ }^{15}$ Central scotoma (target II:4:e) of the VF was measured in a similar fashion. The binocular VF areas and central relative scotoma areas were then measured and analyzed by a computer, using the software Scion Image, available at: http://www.scioncorp.com (Scion Corporation, Maryland, USA). With this method, in normal, healthy subjects the areas of binocular VF diameters of $20^{\circ}, 40^{\circ}$ and 
$70^{\circ}$, are $18.1 \mathrm{~cm}^{2}, 70.9 \mathrm{~cm}^{2}$ and $221.7 \mathrm{~cm}^{2}$, respectively. No measurable visual fields, using (II-4-e, V-4-e) targets, were found in eight patients $(8 / 49 ; 16 \%)$, and in another 13 patients $(13 / 49 ; 27 \%)$ only the largest (V-4-e) target was detected.

\section{Self-reported questionnaire on Vision-Related Quality of life}

The patients rated their performance in a variety of everyday task of activities using the 25-item NEI-VFQ-25, which has been found to be both reliable and valid for use in patients with retinal disease. ${ }^{16,17}$ Subscales and items used in this study are shown in Table 1. Item responses were adjusted for directionality and changed so that high scores reflect patients with good vision/health. Scores were rated on a scale of 0 to 100 , and subscale scores were created by averaging their adjusted item responses. Participants' responses were excluded from specific items if they had stopped the activity for reasons other than poor eyesight.

The questionnaire was administered to all participants, and the patients completed it by themselves, unless their eyesight was too poor to enable reading. In these cases, the examiner $\mathrm{MB}$, read the questionnaire for the patients, in a

Table I Subscales used in the 25-item National Eye Institute Visual Function Questionnaire (NEI-VFQ-25)

\begin{tabular}{ll}
\hline Subscale & Item \\
\hline General health & Five level health rating \\
General vision & Six-level vision rating \\
Ocular pain & Eye pain keeps you from activities \\
Amplitude of eye pain & Reading ordinary print in newspapers \\
Near vision & Work or hobbies that require you to see well up \\
close Finding something on a crowded shelf & Reading street or shop signs \\
Far vision & Going down stairs in dim light \\
& Going out to see movies, plays, sport events \\
Seeing how people react to things you say \\
Visiting other people \\
Wocial function
\end{tabular}

neutral, uniform manner. The five patients examined at their home clinic, had their questionnaires sent by mail $(n=3)$, or had an interview over the phone $(n=2)$.

\section{Statistical analysis}

The mean value, standard deviation (SD) and the median for the overall NEI-VFQ score and for each subscale was computed. Spearman's rank correlation analyses were used to assess the associations between the objective visual functional results (WVA, WLCVA, binocular near vision, the merged areas of binocular V:4e target and II-4-e target, as well as the merged central scotoma area to the II:4e target), and the subscale responses from the VFQ-25 questionnaires. Monocular measurements of VA, LCVA were removed from the analyses as they did not provide any additional information.

The patients were grouped according to their results from each type of visual function measurement. The cut-off point for the WVA groups was "better than $20 / 400$ ” and " $20 / 400$ or worse", and for WLCVA it was "able to see the chart (10\%)" and "not able to see the chart (10\%)". For binocular near VA the cut-off point was "able to read text" and "not able to read text"; for the merged areas of the binocular (V-4e target) the cut-off point was VF area of " $>200 \mathrm{~cm}^{2}$ " and the VF area of " $<200 \mathrm{~cm}^{2}$ "; and finally for the merged central scotoma area (II-4-e target) the patients were grouped into "no or small $\left(<20 \mathrm{~cm}^{2}\right)$ centrally situated scotoma" (within $40^{\circ}$ ) of VF or "large/not measurable $\left(>20 \mathrm{~cm}^{2}\right)$ centrally situated scotoma of the VF (within $40^{\circ}$ ). Mean subscale scores were adjusted for age and gender, using univariate analyses of variance with age and sex as covariates in the model, and then calculated for each group of functional loss.

All statistical analyses were carried out using SPSS 16.0 (Statistical Package for the Social Sciences for MS Windows, SPSS Inc, Chicago, IL).

\section{Results}

In the sample of 49 patients, VA decreased with increasing age (Figure 1). Overall the females had better VA, but this difference was not statistically significant (data not shown).

The distribution of the NEI-VFQ-25 composite score and its subscales is presented in Table 2. Scores for general vision, near vision, far vision, social functioning and color vision were lowest, and those for general health, ocular pain, and mental health were highest.

The results for all subscales except mental health deteriorated significantly with increasing age $(P$ values shown in Table 3). 


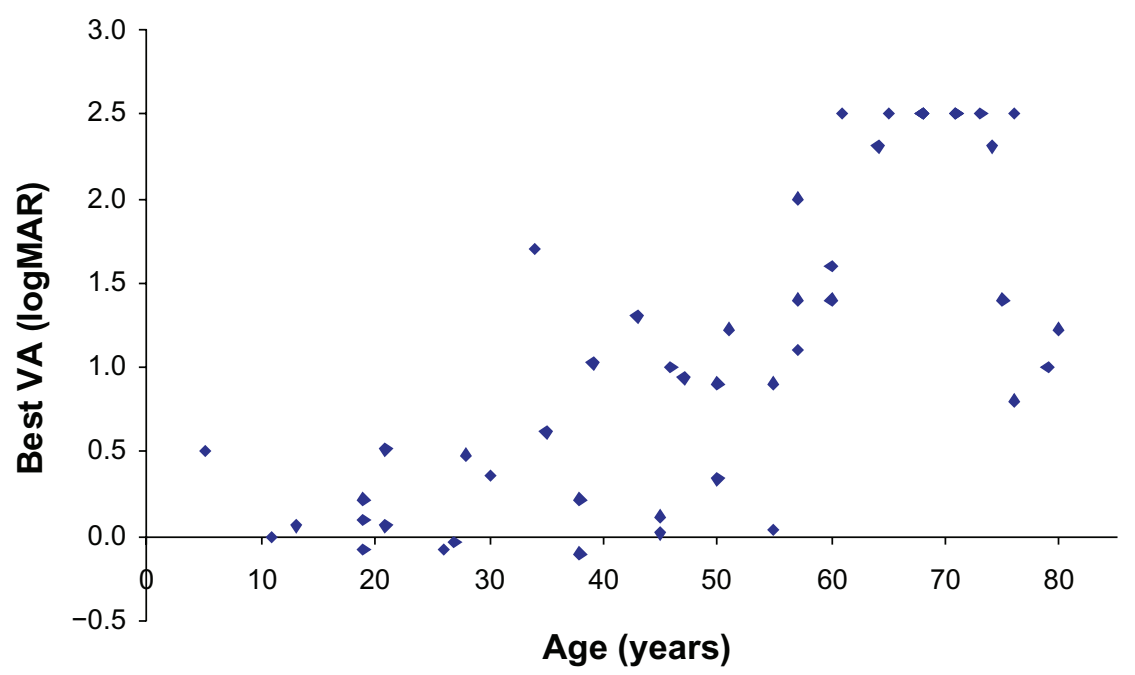

Figure I The relationship between better eye visual acuity and age in patients with retinitis pigmentosa of Bothnia type.

Table 3 shows the Spearman's correlation coefficients between the BD patients' questionnaire responses by subscales and WVA, WLCVA, binocular near vision, the merged VF areas of binocular V-4-e target, and the merged area of the central scotoma to the II-4-e target. Similar results were found between the merged binocular VF areas of the two targets measured V-4-e and II-4-e, therefore the correlations for the II-4-e target is not shown in Table 3.

The BD patients' responses to a majority of the subscales used were significantly correlated with several clinical vision measures. Across the subscales the correlations were substantial and similar for WVA, WLCVA, and binocular near vision. The merged VF areas of binocular V-4-e target and the merged areas of the central scotoma (II-4-e target) also showed significant correlations with the questionnaire responses but there were fewer significant correlations and they were of lower magnitude.

General health was significantly associated with age but there were only weak associations with some of the vision measures (WVA, VA, binocular near VA), and the VF measurements were not related at all.

The subscales mental health, role difficulty, and ocular pain had a similar pattern of correlations between the patients' responses to the questionnaire items by subscales and the vision measures, with strong correlations for WVA, WLCVA, and binocular near VA and surprisingly few significant correlations for the merged VF areas of binocular $\mathrm{V}: 4 \mathrm{e}$ target and the merged central scotoma to the II:4e target areas.

The subscale social function was significantly correlated with all clinical vision measures.
Table 4 presents the mean subscale scores adjusted for age and gender in relation to the two groups of less or more functional loss for each type of visual function measurement. Patients with WVA of 20/400 or worse had significant more difficulty in all the NEI-VFQ subscales except for general health, ocular pain, mental health and role functioning compared with patients who had WVA better than 20/400. Patients not being able to see the LCVA10\% chart showed a similar pattern as the WVA of 20/400 or worse, also with no significant difference for the subscales general health, ocular pain, mental health and role function.

The patients able to read had a better near vision subscale score adjusted for age and gender, compared with patients not being able to read, but surprisingly the results were not significantly different. The subscales far vision and social function were the only subscales with a significant difference between the groups "the patient can read text" or "can't read text".

For the results derived from the visual field analyses, the pattern was completely different. The only subscale in which the difference in subscale score was significantly lower for those patients with a VF area for object V:4e less than $200 \mathrm{~cm}^{2}$ was general vision. There was no significant difference between the responses to all subscales regardless if the patients had "no or small centrally situated scotoma" (II-4-e) or "large/not measurable centrally situated scotoma (II-4-e) of the VF.

It is also important to notice that for the two measurements, VF-area (V-4-e) and central scotoma (II-4-e), there were several subscales in which the patients with greater visual impairment had a better subscale score than patients 


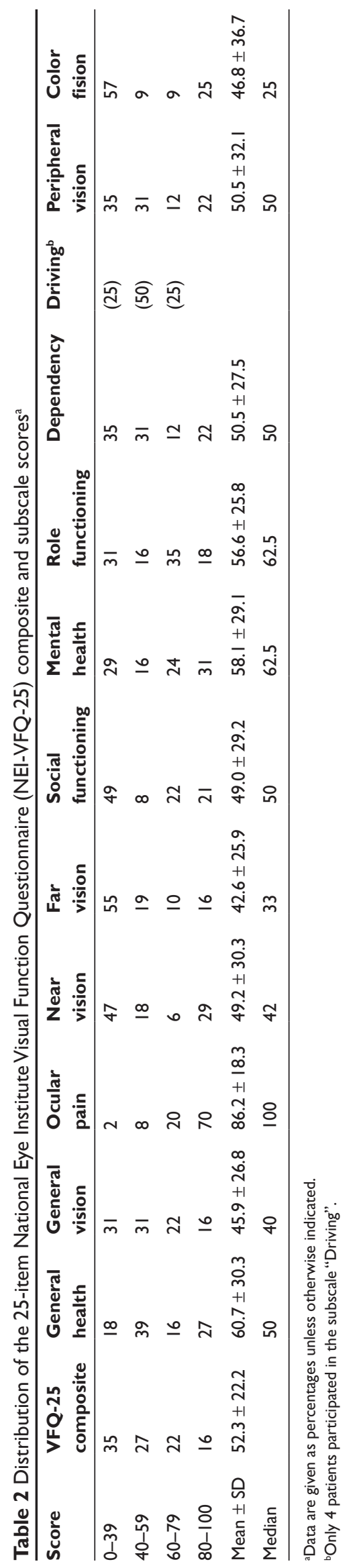

who were less impaired (figures shown in bold in Table 4). This was the case especially with subscales such as General Health, Ocular pain and Mental health.

\section{Discussion}

The BD phenotype expresses progressive maculopathy in early adulthood, in addition to the peripheral retinal degenerative changes like retinal diseases of the RP type. To provide insight into the perceived visual function of this defined phenotype, and to describe the impact of vision loss caused by BD on everyday life, the NEI VFQ-25 questionnaire was used to capture an estimate of vision-targeted health-related quality of life from the patients' perspective. ${ }^{16,17}$ The questionnaire provides an overall score as well as subscale scores which focus on content related to the impact of visual difficulties in everyday life, as well as relevant psychosocial domains such as role-difficulty, social function, and mental health. ${ }^{18}$ The questionnaire is well designed psychometrically and is frequently used in research, which makes it easier to compare patients with different ocular diseases. Several types of visual function WVA, WLCVA, binocular VF area (II-4-e and V-4-e) have previously been shown to decrease with increasing age and progression of the $\mathrm{BD}$ phenotype. ${ }^{10}$

The BD patients' responses to a majority of the NEI VFQ-25 subscales used were significantly correlated with several of the clinical vision measures especially those depending on central VA. As could be expected with the early and progressive decline of VA known in $\mathrm{BD}$, the subscale scores of NEI VFQ-25 for general vision, near vision, far vision, and color vision were lowest (Table 2). These findings are in concordance with a study assessing everyday activities in patients with central retinal degeneration, and juvenile macular dystrophies. ${ }^{19}$ This study found highly significant correlations between activities involving central vision such as reading and the objective measures of central vision, ie, VA, and the area of central scotoma (II-4-e target).

In studies of RP patients, the visual function of the central retina, is known to change relatively slowly compared with more peripherally located retinal functions ${ }^{20}$ On the other hand, patients with RP have also been shown to perceive difficulty in performing common tasks depending on vision, and this difficulty was strongly related to both VA as well as the VF-area. ${ }^{21}$

In the present study the BD patients obtained the highest scores (less impairment) for the subscales general health, ocular pain, and mental health. Previous studies have shown that older adults with sight-threatening eye diseases and visual impairment are prone to depression. ${ }^{22,23}$ Depression is 
Table 3 Spearman's correlation coefficients between the questionnaire subscale responses and weighted visual acuity (WVA) and low contrast (10\%) weighted visual acuity (WLCVA), binocular near vision, the merged areas of binocular V:4e target and the merged central scotoma to the II:4e target in patients with Bothnia dystrophy (the subscale Driving was not included because only 4 patients participated)

\begin{tabular}{|c|c|c|c|c|c|c|}
\hline & Age & WVA & WLCVA & Bin VA near & V:4 bin & scot II:4 bin \\
\hline General health & -0.390 (**) & $-0.333\left(^{*}\right)$ & -0.271 & $-0.319(*)$ & 0.205 & -0.191 \\
\hline$P$ & 0.006 & 0.019 & 0.071 & 0.035 & 0.166 & 0.203 \\
\hline General vision & $-0.714(* *)$ & $-0.843(* *)$ & $-0.733(* *)$ & $-0.807(* *)$ & $0.838(* *)$ & $-0.692(* *)$ \\
\hline$P$ & 0.000 & 0.000 & 0.000 & 0.000 & 0.000 & 0.000 \\
\hline Ocular pain & $-0.449(* *)$ & $-0.363\left(^{*}\right)$ & $-0.404(* *)$ & $-0.362(*)$ & 0.271 & $-0.345(*)$ \\
\hline$P$ & 0.001 & 0.010 & 0.006 & 0.016 & 0.066 & 0.019 \\
\hline Near vision & $-0.717(* *)$ & $-0.835(* *)$ & $-0.77 I(* *)$ & $-0.824(* *)$ & $0.740(* *)$ & $-0.702(* *)$ \\
\hline$P$ & 0.000 & 0.000 & 0.000 & 0.000 & 0.000 & 0.000 \\
\hline Distance vision & $-0.716(* *)$ & $-0.8 \mathrm{II}(* *)$ & $-0.674(* *)$ & $-0.830(* *)$ & $0.7 \mid 4(* *)$ & $-0.656(* *)$ \\
\hline$P$ & 0.000 & 0.000 & 0.000 & 0.000 & 0.000 & 0.000 \\
\hline Social functioning & -0.643 (**) & $-0.744(* *)$ & -0.663 (**) & $-0.784(* *)$ & $0.654(* *)$ & -0.601 (**) \\
\hline$P$ & 0.000 & 0.000 & 0.000 & 0.000 & 0.000 & 0.000 \\
\hline Mental health & -0.258 & $-0.368(* *)$ & $-0.330(*)$ & $-0.37 I(*)$ & 0.188 & -0.085 \\
\hline$P$ & 0.074 & 0.009 & 0.027 & 0.013 & 0.206 & 0.576 \\
\hline Role difficult & $-0.363\left(^{*}\right)$ & $-0.408(* *)$ & $-0.346(*)$ & $-0.367(*)$ & 0.268 & $-0.353(*)$ \\
\hline$P$ & 0.010 & 0.004 & 0.020 & 0.014 & 0.068 & 0.016 \\
\hline Dependency & $-0.4 \mathrm{II}(* *)$ & $-0.564(* *)$ & $-0.557(* *)$ & $-0.564(* *)$ & $0.432(* *)$ & -0.272 \\
\hline$P$ & 0.003 & 0.000 & 0.000 & 0.000 & 0.002 & 0.068 \\
\hline Color vision & $-0.666(* *)$ & $-0.742(* *)$ & $-0.653(* *)$ & $-0.73 \mathrm{I}(* *)$ & $0.708(* *)$ & $-0.653(* *)$ \\
\hline$P$ & 0.000 & 0.000 & 0.000 & 0.000 & 0.000 & 0.000 \\
\hline Peripheral vis & $-0.693(* *)$ & $-0.750(* *)$ & $-0.654(* *)$ & $-0.756(* *)$ & 0.760 (**) & $-0.623(* *)$ \\
\hline$P$ & 0.000 & 0.000 & 0.000 & 0.000 & 0.000 & 0.000 \\
\hline
\end{tabular}

**Correlation significant at the $0.0 \mathrm{I}$ level (2-tailed).

*Correlation significant at the 0.05 level (2-tailed).

also associated with lower scores in distance vision activities and peripheral vision, ie, depressed patients expressed more difficulty. ${ }^{24}$

The psychosocially oriented VFQ subscales such as role difficulty, dependency, and mental health, are influenced by and reflect the presence of depression. For the subscales ocular pain, mental health and role functioning there was no significant difference in scores between BD-patients with more or less visual impairment. In fact, several subscales (Table 4) show better age and gender adjusted scores for patients with advanced BD and all subscales except mental health deteriorated significantly with increasing age (Table 3). It has been shown that the longer the duration of perceived vision loss, the less it is associated with emotional distress. ${ }^{25}$ The reason for no signs of accelerating depression related to the increasing visual impairment in BD patients 
Table 4 Comparison of adjusted mean scale scores for weighted visual acuity, weighted low contrast acuity (I0\%), near visual acuity, visual field area V:4e, and scotoma ${ }^{\mathrm{b}}$

\begin{tabular}{|c|c|c|c|c|c|c|c|c|c|c|}
\hline \multirow[t]{2}{*}{ NEI-VFQ scale } & \multicolumn{2}{|c|}{$\begin{array}{l}\text { Weighted visual } \\
\text { acuity }\end{array}$} & \multicolumn{2}{|c|}{$\begin{array}{l}\text { Weighted low } \\
\text { contrast acuity (10\%) }\end{array}$} & \multicolumn{2}{|c|}{$\begin{array}{l}\text { Near visual } \\
\text { acuity }\end{array}$} & \multicolumn{2}{|c|}{$\begin{array}{l}\text { Visual field area } \\
\text { (V-4-e) }\end{array}$} & \multicolumn{2}{|c|}{$\begin{array}{l}\text { Central scotoma } \\
\text { (II-4-e) }\end{array}$} \\
\hline & $\begin{array}{l}>20 / 400 \\
(n=27)\end{array}$ & $\begin{array}{l}\leq 20 / 400 \\
(n=20)\end{array}$ & $\begin{array}{l}\text { Can see } \\
(n=2 I)\end{array}$ & $\begin{array}{l}\text { Not able } \\
(n=28)\end{array}$ & $\begin{array}{l}\text { Can read } \\
(n=34)\end{array}$ & $\begin{array}{l}\text { Not able } \\
(n=15)\end{array}$ & $\begin{array}{l}>200 \mathrm{~cm}^{2} \\
(\mathrm{n}=25)\end{array}$ & $\begin{array}{l}<200 \mathrm{~cm}^{2} \\
(\mathrm{n}=23)\end{array}$ & $\begin{array}{l}\text { no/small } \\
\text { scotoma } \\
(n=26)\end{array}$ & $\begin{array}{l}\text { Large } \\
\text { scotoma } \\
(n=23)\end{array}$ \\
\hline General health & 64.4 & 55.7 & 63.4 & 57.0 & 63.8 & 57.4 & 52.1 & 69.5 & 57.8 & 64.2 \\
\hline General vision & $54.4^{a}$ & 34.6 & $56.2^{\mathrm{a}}$ & 37.6 & 49.2 & 36.5 & $57.7^{\mathrm{a}}$ & 33.7 & 47.6 & 44.5 \\
\hline Ocular pain & 86.0 & 86.5 & 88.5 & 83.9 & 86.0 & 84.5 & 81.0 & 93.2 & 86.1 & 89.1 \\
\hline Near vision & $59.1^{a}$ & 35.9 & $63.8^{\mathrm{a}}$ & 37.2 & 52.1 & 40.6 & 53.1 & 43.9 & 54.5 & 42.2 \\
\hline Far vision & $50.5^{a}$ & 32.1 & 48.8 & 36.6 & $46.9^{a}$ & 30.2 & 45.2 & 39.3 & 41.4 & 43.3 \\
\hline Social function & $60.1^{a}$ & 34.1 & $60.2^{\mathrm{a}}$ & 39.3 & $54.3^{\mathrm{a}}$ & 34.0 & 57.6 & 39.3 & 51.4 & 46.2 \\
\hline Mental health & 64.6 & 49.4 & 61.4 & 52.8 & 57.0 & 53.2 & 57.4 & 59.3 & 48.6 & 69.6 \\
\hline Role functioning & 59.4 & 52.9 & 56.0 & 56.4 & 55.9 & 58.0 & 52.4 & 60.6 & 59.7 & 52.5 \\
\hline Dependency & $60.5^{a}$ & 37.2 & $62.0^{\mathrm{a}}$ & 38.9 & 52.5 & 43.3 & 60.4 & 39.1 & 52.7 & 46.7 \\
\hline Peripheral vision & $61.5^{\mathrm{a}}$ & 35.8 & $59.0^{\mathrm{a}}$ & 41.1 & 54.6 & 39.0 & 59.2 & 40.5 & 59.0 & 41.3 \\
\hline Color vision & $60.0^{\mathrm{a}}$ & 33.3 & $61.0^{\mathrm{a}}$ & 35.6 & 49.3 & 39.3 & 51.3 & 40.7 & 46.9 & 45.0 \\
\hline
\end{tabular}

aThe difference between the groups is significant $(P<0.05)$.

${ }^{b}$ Adjusted for age and gender.

Notes: Figures in boldface show a better adjusted mean subscale score for patients with greater visual impairment compared with those with less impairment.

might well be that the patients have adjusted to their diagnosis to a high degree.

The BD patients' overall responses to a majority of the subscales of NEI VFQ-25 were substantially and similarly associated with WVA, WLCVA, and binocular near vision (Table 3). Surprisingly, the merged VF areas (V-4-e target) and the merged areas of the central scotoma (II-4-e target) showed fewer significant associations of lower magnitude with the questionnaire responses. There was no significant difference in adjusted subscale scores for patients with or without extensive VF impairment except for the subscale General Vision (Table 4). Similarly, there was no difference in adjusted responses for patients with or without a centrally extensive scotoma (II-4-e target).

Measurements of the visual field may not be the best way to capture an estimate of vision-targeted health related quality of life from the BD patients' perspective. The reason for this is not clear. A previous study of the BD phenotype has shown that the VF impairment begins with affection of the central and/or paracentral VF. The VF defects progress with time, finally affecting the peripheral borders of the VFs in the advanced disease of BD. ${ }^{6}$ We may speculate that the BD patients may actually perceive less impact of the midperipheral VF defects in daily life compared to the more concentric loss of VF area in classical phenotypes of RP. The finding of low correlation of NEI VFQ-25 and VF impairment may also be an indication of an ability to adapt to this pattern of progressive VF loss in the BD phenotype. Further research of the phenotypical expression of mutations in the RLBP 1 gene, found in this geographic area, can give additional knowledge of visual function outcome in this patient group. ${ }^{26}$

To conclude, the BD patients' responses to a majority of the NEI VFQ-25 subscales were significantly correlated with several of the clinical vision measures especially those depending on central VA. On the contrary, the progression of VF defects typical for the BD phenotype does not seem to affect the self-perceived quality of life to a significant degree. This finding might be an indication of ability to adapt to this type of progressive VF loss of the BD phenotype. The $\mathrm{BD}$ phenotype has a significant impact on multiple domains of daily living, but there are no signs of worsening depression related to the increasing visual impairment.

\section{Acknowledgments}

This work was supported by grants from Crown Princess Margaretha's Foundation for Vision Research (KMA), and The Swedish Society of Medicine, Stockholm, Sweden. The NEI-VFQ was developed by RAND and sponsored by the National Eye Institute, USA. The Swedish translated form of the questionnaire was contributed by the Early Manifest Glaucoma Trial, (EMGT), Malmö, Sweden.

\section{Disclosures}

The authors report no conflicts of interest. 


\section{References}

1. Burstedt MS, Sandgren O, Holmgren G, et al. Bothnia dystrophy caused by mutations in the cellular retinaldehyde-binding protein gene (RLBP1) on chromosome 15q26. Invest Ophthalmol Vis Sci. 1999;40:995-1000.

2. Maw MA, Kennedy B, Knight A, et al. Mutation of the gene encoding cellular retinaldehyde-binding protein in autosomal recessive retinitis pigmentosa. Nat Genet. 1997;17:198-200.

3. Morimura H, Berson EL, Dryja TP. Recessive mutations in the RLBPI gene encoding cellular retinaldehyde-binding protein in a form of retinitis punctata albescens. Invest Ophthalmol Vis Sci. 1999;40:1000-1004.

4. Katsanis N, Shroyer NF, Lewis RA, et al. Fundus albipunctatus and retinitis punctata albescens in a pedigree with an R150Q mutation in RLBP1. Clin Genet. 2001;59(6):424-429.

5. Eichers ER, Green JS, Stockton DW, et al. Newfoundland rod-cone dystrophy, an early-onset retinal dystrophy, is caused by splice-junction mutations in RLBP1. Am J Hum Genet. 2002;70:955-964.

6. Burstedt MS, Forsman-Semb K, Golovleva I, et al. Ocular phenotype of bothnia dystrophy, an autosomal recessive retinitis pigmentosa associated with an R234W mutation in the RLBP1 gene. Arch Ophthalmol. 2001;119:260-267.

7. Burstedt MS, Sandgren O, Golovleva I, et al. Retinal function in Bothnia dystrophy. An electrophysiological study. Vision Res. 2003;43: 2559-2571.

8. Burstedt MS, Sandgren O, Golovleva, et al. Effects of prolonged dark adaptation in patients with retinitis pigmentosa of Bothnia type: an electrophysiological study. Doc Ophthalmol. 2008;116:193-205.

9. Grover S, Fishman GA, Brown J Jr. Patterns of visual field progression in patients with retinitis pigmentosa. Ophthalmology. 1998;105:1069-1075.

10. Burstedt MS, Monestam E, Sandgren O. Associations between specific measures of vision and vision-related quality of life in patients with Bothnia dystrophy, a defined type of retinitis pigmentosa. Retina. 2005;25:317-323.

11. WHO, Statistical classification of diseases and related health problems, 10th revised ed. 1992; World Health Organization, Geneva.

12. Steinberg EP, Tielsch JM, Schein OD, et al. National study of cataract surgery outcomes. Variation in 4-month postoperative outcomes as reflected in multiple outcome measures. Ophthalmology. 1994;101:1131-1140.

13. Scott IU, Smiddy WE, Feuer W Merikansky A. Vitreoretinal surgery outcomes: results of a patient satisfaction/functional status survey. Ophthalmology. 1998;105:795-803.
14. Holladay JT, Prager TC. Mean visual acuity. Am J Ophthalmol. 1991; 111:372-374.

15. Arditi A. The volyme visual field: a basis for functional perimetry. Clin Vision Sci. 1988;3:173-183.

16. Mangione CM, Berry S, Spritzer K, et al. Identifying the content area for the 51-item National Eye Institute Visual Function Questionnaire: results from focus groups with visually impaired persons. Arch Ophthalmol. 1998; 116:227-233.

17. Mangione CM, Lee PP, Gutierrez PR, et al. Development of the 25-item National Eye Institute Visual Function Questionnaire. Arch Ophthalmol. 2001;119:1050-1058.

18. Mangione CM, Lee PP, Pitts J, et al. Psychometric properties of the National Eye Institute Visual Function Questionnaire (NEI-VFQ). NEIVFQ Field Test Investigators. Arch Ophthalmol. 1998;116:1496-1504.

19. Szlyk JP, Fishman GA, Grover S, Revelins BI Derlacki DJ. Difficulty in performing everyday activities in patients with juvenile macular dystrophies: comparison with patients with retinitis pigmentosa. $\mathrm{Br} J$ Ophthalmol. 1998;82:1372-1376.

20. Holopigian K, Greenstein V, Seiple W, et al. Rates of change differ among measures of visual function in patients with retinitis pigmentosa. Ophthalmology. 1996;103:398-405.

21. Szlyk JP, Fishman GA, Alexander KR, et al. Relationship between difficulty in performing daily activities and clinical measures of visual function in patients with retinitis pigmentosa. Arch Ophthalmol. 1997;115:53-59.

22. Rovner BW, Zisselman PM, Shmuely-Dulitzki Y. Depression and disability in older people with impaired vision: a follow-up study. $\mathrm{J} \mathrm{Am}$ Geriatr Soc. 1996;44:181-184.

23. Brody BL, Gamst AC, Williams RA, et al. Depression, visual acuity, comorbidity, and disability associated with age-related macular degeneration. Ophthalmology. 2001;108:1893-1900; discussion 1900-1901.

24. Owsley C, McGwin G Jr. Depression and the 25-item National Eye Institute Visual Function Questionnaire in older adults. Ophthalmology. 2004;111:2259-2264.

25. Williams RA, Brody BL, Thomas RG, et al. The psychosocial impact of macular degeneration. Arch Ophthalmol. 1998;116:514-520.

26. Köhn L, Burstedt MSI, Jonsson F, et al. Carrier of R14W in carbonic anhydrase IV presents Bothnia Dystrophy phenotype caused by two allelic mutations in RLBP1. Invest Ophthal Vis Sci. 2008;49:3172-3177.
Clinical Ophthalmology

\section{Publish your work in this journal}

Clinical Ophthalmology is an international, peer-reviewed journal covering all subspecialties within ophthalmology. Key topics include: Optometry; Visual science; Pharmacology and drug therapy in eye diseases; Basic Sciences; Primary and Secondary eye care; Patient Safety and Quality of Care Improvements. This journal is indexed on Submit your manuscript here: http://www.dovepress.com/clinical-ophthalmology-journal

\section{Dovepress}

PubMed Central and CAS, and is the official journal of The Society of Clinical Ophthalmology (SCO). The manuscript management system is completely online and includes a very quick and fair peer-review system, which is all easy to use. Visit http://www.dovepress.com/ testimonials.php to read real quotes from published authors. 